\title{
Effect of Oil Contamination on Lime Stabilized Soil
}

\author{
Ochepo, J. and Joseph, V. ${ }^{1)}$ \\ ${ }^{1)}$ Department of Civil Engineering, Ahmadu Bello University, Zaria, Nigeria. \\ E-Mail: ochepo1@gmail.com
}

\begin{abstract}
This study was carried out to evaluate the effect of spent oil contamination on the strength of lime stabilized soil. Laterite soil was stabilized with lime in percentages of $0,2,4,6$, and $8 \%$ of the dry weight of soil. Specimens were prepared for UCS and CBR. The specimens for UCS were cured for 7, 14 and 28 days; while the specimens for CBR were cured for 4 days. Contamination of the specimens was achieved by soaking in spent oil medium in a plastic bowl for 48 hours after the respective curing periods. The uncontaminated soil and the contaminated soil were both tested for UCS and CBR. The results obtained show that the strength of lime stabilized soil decreased when contaminated with oil. The value of the UCS decreased by about 46, 23 and $13 \%$ on the average for soil-lime mixture cured for 7, 14 and 28 days, respectively. Similarly, the CBR of the soil-lime mixture reduced by about $35 \%$. It was also observed that the resistance to loss in strength increased with lime content and curing period. This results show for all practical purposes that a lime stabilized pavement structure exposed to oil contamination is susceptible to failure as a result of reduction in strength and bearing capacity due to oil contamination.
\end{abstract}

KEYWORDS: Lime, Oil contamination, Unconfined compressive strength, California bearing ratio.

\section{INTRODUCTION}

The Niger Delta area of Nigeria is made up of about $70,000 \mathrm{~km}^{2}$ of wetland, primarily formed by sediment deposition. The population of the area is about 20 million people comprising of 40 different ethnic groups. It makes up about $7.5 \%$ of Nigeria's total land mass. It is the largest wetland and maintains the thirdlargest drainage area in Africa.

Nigeria has a total of 159 oil fields and 1481 oil wells in operation in this area. The oil operations constitute the backbone of the nation's economy. In 2000, oil and gas exports derived from this area accounted for more than $98 \%$ of the export earnings and about $83 \%$ of the federal government revenues, generating more than $40 \%$ of the gross domestic

Accepted for Publication on 2/11/2013. product (GDP). It also provides about 95\% of the foreign exchange earnings and about $65 \%$ of the government's budgetary revenues.

Oil spillage in Nigeria is a common occurrence because of the oil exploration activities. Oil drilling began in the country in 1958. From 1958 to date, it is estimated that about 9 to 13 million barrels of oil have spilled. The government estimates that about 7,000 spills occurred between 1970 and 2000. Causes of this spillage include corrosion of pipelines and tankers which accounts for $50 \%$ of all spills, $28 \%$ is due to sabotage, oil production operations account for about $21 \%$, while $1 \%$ of the spills is attributed to inadequate or non-functional production equipment.

Oil spillage has a major impact on the ecosystem. These petroleum products released contaminate the soil, thus subjecting the soil to a change in its engineering properties, making it unsuitable for use as 
a sub-base and base material for road construction, topping layer for car parker, landfill cover material and detrimental to buildings and structures standing on it due to loss of bearing capacity. A study carried out by Dana and Ahmad (2011) on the geotechnical properties of oil contaminated soil showed that the bearing capacity of the soil decreases and the compressibility increases because of oil contamination. A similar study carried out to evaluate the compressibility and strength properties of oil contaminated laterite soil showed an increase in compressibility and a decrease in unconfined compressive strength of contaminated soil relative to the uncontaminated soil (Ijimdiya and Igboro, 2012). Evgin and Das (1992) conducted a series of triaxial tests on oil contaminated and uncontaminated clean sands. The results obtained showed that the friction angle drastically reduced for oil saturated loose and dense samples. On the other hand, the volumetric strain increased. These findings suggested that settlement of footing would increase as a result of oil contamination. Khamehchivan et al. (2007) investigated the effect of crude oil on geotechnical properties of sandy-soil and clay. The results showed that the Atterberg limits decreased with the increase in oil percentage. The increase of oil content in the soil samples also caused a decrease in maximum dry density, optimum water content, porosity and shear strength. Shin and Das (2001) reported that the load carrying capacity of oil partially saturated sand decreased with oil content. The study was carried out for oil content in the range of 0 to $6 \%$.

One of the measures aiming at improving the geotechnical properties of oil contaminated soil is by chemical stabilization with additives such as lime and fly ash. Report by Amer et al. (2005) showed an increase in unconfined compressive strength when oil contaminated soil was treated with cement and cement by-pass dust. Similarly, Shah et al. (2003) reported stabilizing fuel contaminated soil with lime, fly ash and cement as well as an admixture of lime, fly ash and cement in different combinations. It was observed that the geotechnical properties of the contaminated soil were improved by way of cation exchange, agglomeration and pozzolanic actions. The best result was obtained when $10 \%$ lime, $5 \%$ fly ash and $5 \%$ cement was added to the contaminated soil. The improvement in the geotechnical properties of the soil was attributed to neo-formations such as calcium silicate hydrates which bind the soil particles. Formation of stable complex between oil and metallic cations was thought to reduce leachable oil.

These research outcomes indicate that the geotechnical properties of oil contaminated soil can be effectively improved with chemical treatment.

This study, however, seeks to investigate the effect of oil contamination on lime stabilized laterite soil. Laterite soil as defined by ISSMFE progress report (1982/1985) is a soil belonging to horizon A or B of well drained profile developed under humid tropical climates with clay fraction constituted essentially of the kaolinite group and of iron or aluminium hydrate oxides. This soil according to Ola (1975) can be economically stabilized with lime. Osinubi (1999, 2006) reported increases in UCS and CBR when laterite soil was stabilized with $0-8 \%$ lime content. Eades and Grim (1960) reported that in a soil-lime mixture the reaction occurring is between lime and clay minerals. Kaolin was shown to require $4-6 \%$ of lime for the development of maximum strength; while montmorillonite and illite mineral required in excess of $4-6 \%$ of lime.

In this study, laterite soil was stabilized with $0-8 \%$ lime by weight of the dry soil as in Osinubi (1999, 2006). The test specimens prepared were cured in a humidity room at $100 \%$ relative humidity and a temperature of $25 \pm 2^{\circ} \mathrm{C}$ before immersion in the contaminated medium.

The findings of this study will help engineers gain insight into the behaviour of a stabilized base or subbase structure in a petroleum contaminated environment.

\section{MATERIALS AND METHODS}

\section{Soil}

The soil used in this study is a natural reddish 
brown laterite soil which was collected from a borrow pit in Shika village, Zaria Local Government Area, Kaduna State in the Northern part of Nigeria (latitude $11^{\circ} 15^{\prime} \mathrm{N}$ and longitude $7^{\circ} 45^{\prime} \mathrm{E}$ ), by using the method of disturbed sampling.

\section{Spent oil}

The spent oil used was collected from Oando lubrication workshop adjacent to Ahmadu Bello University main gate, Samaru Campus.

\section{Lime}

Lime was collected from the National Research Institute of Chemical Technology in Zaria.

\section{Methods}

The laboratory tests to determine the index properties of the natural soil were conducted in accordance with BS 1377 (1990). The results are as shown in Table 1. The physical properties of the spent oil were also determined as shown in Table 2. Oxide composition of lime was determined at the Centre for Energy Research and Training (CERT), A. B. U., Zaria, using the method of Energy Dispersive X-Ray Fluorescence (EDXRF). The results are shown in Table 3.

\section{Compaction and Unconfined Compressive Strength Tests}

The moisture-density relationships of the soil and the soil-lime mixture were determined by compaction test in accordance with BS 1377 (1990) and BS 1924 (1990) using the British Standard light (Standard Proctor), (BSL), compactive effort. The Standard Proctor compactive effort corresponds to $592.5 \mathrm{~kJ} / \mathrm{m}^{3}$ of energy.

The samples of soil-lime mixtures were prepared by mixing the desired proportions of potable water, soil and lime. The percentages of lime ranged from 0 to 8 $\%$ by weight of dry soil. The soil-lime mixtures were thoroughly mixed in a tray to obtain a uniform colour. The British Standard light compactive effort used consisted of energy derived from $2.5 \mathrm{~kg}$ rammer falling through $30 \mathrm{~cm}$ on three layers each receiving 27 blows. A minimum of five determinations were conducted within which the maximum dry density and the optimum moisture content was obtained.

The unconfined compression test was carried out in accordance with BS 1377 (1990), part 7. The required amount of water determined from moisture-density relationships for soil-lime mixtures was added to the dry soil-lime mixed samples. The specimens were cured for 7, 14 and 28 days in the case of unconfined compression. The CBR tests were carried out in accordance with BS 1377 (1990), part 8, and specimens were cured for 4 days.

The contamination process involved dewaxing the specimen top and bottom after curing for 7, 14 and 28 days, respectively, and immersing in a plastic container filled with the oil for 48 hours. The CBR specimens were similarly contaminated by immersing in oil for 48 hours after 4-day curing. The specimens were then removed at the end of the 48 hours, wiped clean and tested for UCS and CBR values.

\section{Table 1. Basic Properties of Soil Samples}

\begin{tabular}{|l|l|}
\hline Properties & Quantity \\
\hline Natural Moisture Content, (\%) & 5.8 \\
Liquid Limit, (\%) & 46.60 \\
Plastic Limit, (\%) & 32.4 \\
Plasticity Index, (\%) & 14.20 \\
Percentage Passing BS.No.200 Sieve & 73.5 \\
Specific Gravity & 2.63 \\
AASHTO Classification & A-7-6 \\
USCS Classification & CL \\
MDD (BSL), (Mg/m ${ }^{3}$ ) & 1.70 \\
OMC (BSL), (\%) & 18.00 \\
pH Value & 6.7 \\
Colour & Reddish Brown \\
Dominant Clay Mineral & Kaolinite \\
\hline
\end{tabular}




\section{RESULTS AND DISCUSSION}

\section{Properties of Materials}

The index properties of the natural soil are summarized and shown in Table 1 . The soil has a liquid limit of $46 \%$ and a plasticity index of $14 \%$. From the combined results of the Atterberg limits and the sieve analysis, the soil was classified as A-7-6 and
CL in accordance with AASHTO and the Unified Soil Classification System (USCS), respectively.

Table 2 shows the properties of the spent petroleum oil used in this study. The specific gravity and density of the spent oil were 0.7 and $0.76 \mathrm{~g} / \mathrm{cm}^{3}$, respectively.

Table 3 is the result of the oxide composition of the lime used in the test. The percentages of $\mathrm{CaO}, \mathrm{SiO}_{2}$ and $\mathrm{Al}_{2} \mathrm{O}_{3}$ were $43.93,37.71,11.61 \%$, respectively.

Table 2. Summary of the Petroleum Oil Used in the Study

\begin{tabular}{|l|c|c|c|c|c|}
\hline Property & Specific gravity & $\begin{array}{c}\text { Flash point } \\
\left.\mathbf{(}^{\mathbf{0}} \mathbf{C}\right)\end{array}$ & $\begin{array}{c}\text { Fire point } \\
(\mathbf{0} \mathbf{C})\end{array}$ & $\begin{array}{c}\text { Viscosity } \\
(\mathbf{c P})\end{array}$ & $\begin{array}{c}\text { Density } \\
\left(\mathbf{g} / \mathbf{c m}^{\mathbf{3}}\right)\end{array}$ \\
\hline Value & 0.7 & 168 & 220 & 1.17 & 0.76 \\
\hline
\end{tabular}

Table 3. Oxide Composition of Lime

\begin{tabular}{|l|c|c|c|c|c|c|c|}
\hline Oxide Composition & $\mathrm{CaO}$ & $\mathrm{SiO}_{2}$ & $\mathrm{Al}_{2} \mathrm{O}_{3}$ & $\mathrm{Fe}_{2} \mathrm{O}_{3}$ & $\mathrm{Mn}_{2} \mathrm{O}_{3}$ & $\mathrm{~K}_{2} \mathrm{O}$ & $\mathrm{TiO}_{2}$ \\
\hline Concentration (\%) & 43.93 & 37.71 & 11.61 & 0.17 & 0.11 & 0.18 & 0.93 \\
\hline
\end{tabular}

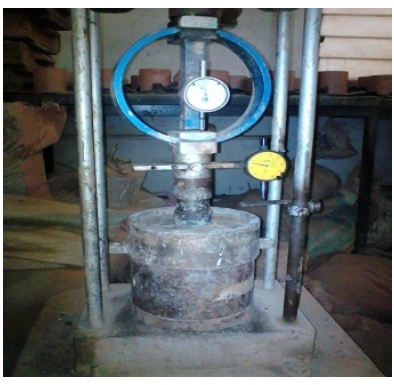

Figure (1a): CBR test of oil treated soil

\section{Effect of Oil Contamination on UCS}

Fig. 2 shows the plot of UCS of the lime treated uncontaminated soil and the oil contaminated lime treated soil. The plot shows an increase of UCS with lime treatment for the lime treated uncontaminated soil at all curing periods. This is as a result of reaction between the soil and the lime which results in the formation of cementitious compounds such as calcium silicate hydrates $(\mathrm{CSH})$ and calcium aluminate hydrates (CAH) and micro fabric changes. Ingles and Metcalf (1972) suggested that lime reacted with the clay

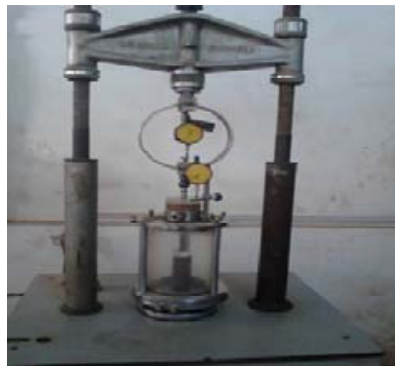

Figure (1b): UCS test of oil treated soil

minerals of the soil to form a tough water insoluble gel of calcium silicate, which cemented the soil particles. This results in the strength increase as recorded in this study.

The effect of oil contamination on the treated soil can also be seen in the plot. It is observed that contaminating the lime treated soil with spent petroleum oil results in the reduction of UCS values of the treated soil. The reduction in strength was observed to be on the average of about 46, 23 and 13\%, respectively, for 7-, 14- and 28-day curing. The 
reduction in strength of the treated soil may be due to the penetration of the liquid oil into the fabric of the treated soil and possible reactions between the hydrocarbon compounds in the oil with the calcium silicate gel. This may have disrupted the stability of the gel and resulted in a material with a lesser strength.

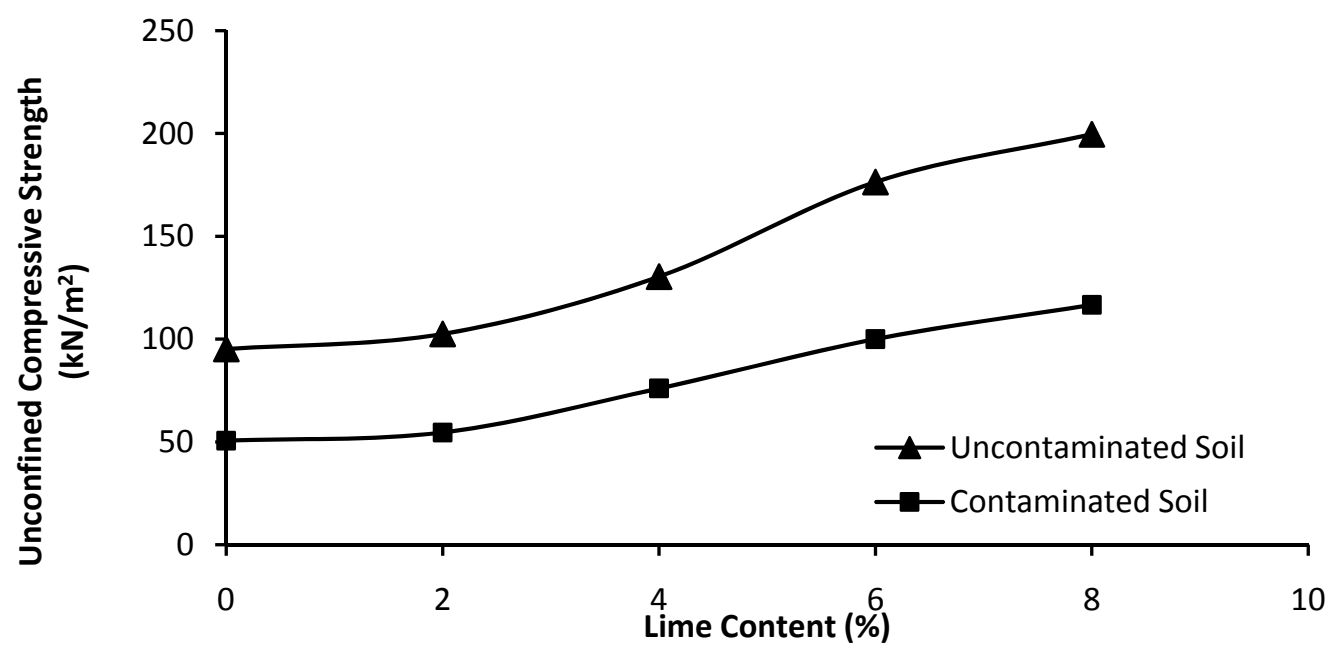

Figure (2a): Variation of UCS with lime content for contaminated and uncontaminated soil-lime mixture (7-day curing)

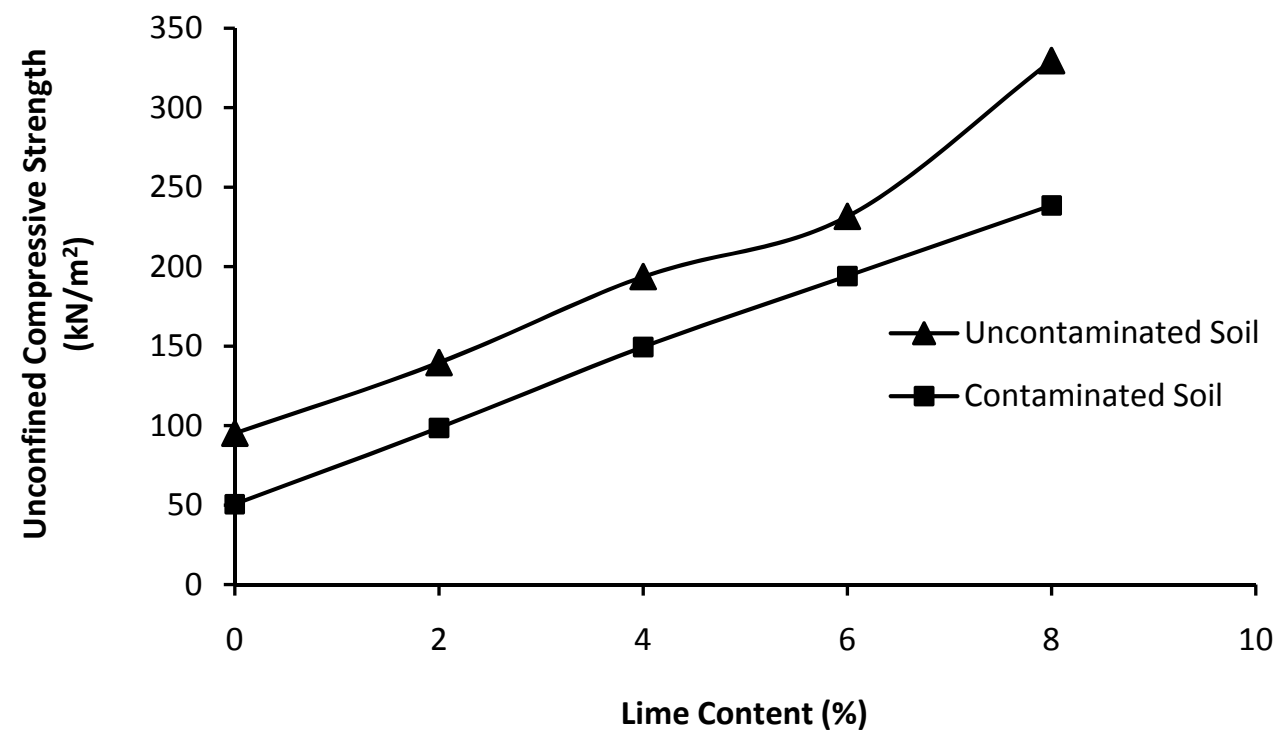

Figure (2b): Variation of UCS with lime content for contaminated and uncontaminated soil-lime mixture (14-day curing) 


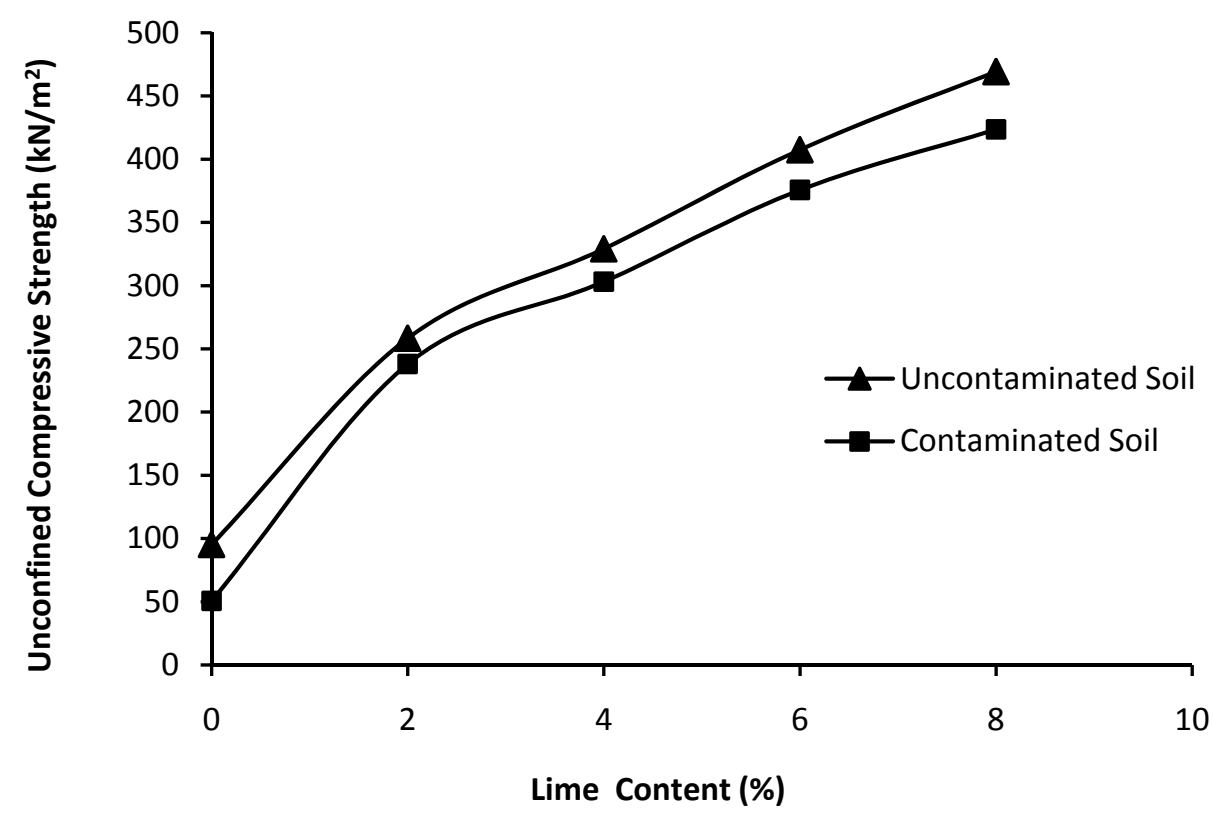

Figure (2c): Variation of UCS with lime content for contaminated and uncontaminated soil-lime mixture (28-day curing)

It is also observed from these results that the reduction in strength due to oil contamination decreases with the curing period. The decrease in strength loss with curing period as observed in these results may be attributed to the degree of strength development which is dependent on the extent of reaction between lime and soil mineral which in turn is a function of time. The mechanism of soil-lime reaction has been reported by many researchers (Clare and Cruchley, 1957; Thompson, 1966; Ormsby and Kinter, 1973; Locat et al., 1990). Addition of lime to soil results in the improvement of soil properties which is due to two types of lime reactions. The first reaction is a colloidal type of reaction which is immediate and is reflected mainly on the workability of the soil. The second reaction is the pozzolanic reaction which is time dependent in which dissolved silica and alumina minerals of clay fraction react with calcium, forming new cementitious compounds such as calcium silicate hydrates and calcium aluminate hydrates, respectively (Narasimha Rao and Rajesekaran, 1996). This reaction is time dependent and results in the formation of the tough water insoluble gel of calcium silicates, which cemented the soil particles. Under favorable conditions, this reaction continues with time producing more cementing materials resulting in a stronger soil matrix.

It appears that the contaminated liquid medium would find it more difficult to penetrate the matrix disrupting the bond for those soil-lime mixtures cured for a longer period of time. This is reflected in Fig. 3 which shows the plot of percent loss in strength, LS and the corresponding resistance to loss in strength, RLS against lime content. The RLS is computed using equation 1.

$$
R L S=\left(1-\Delta q_{u c} / q_{u}\right) 100
$$

where $\Delta q_{u c}$ is the difference between uncontaminated UCS, $\mathrm{q}_{\mathrm{u}}$ and oil contaminated UCS, $\mathrm{q}_{\mathrm{c}}$ values.

It can be observed from this plot that the loss in strength of the contaminated soil decreased while the resistance to loss in strength increased with the increase in lime content at all curing periods. Higher 
value of loss in strength was observed at 7-day curing because the 7-day strength was low as compared to the 14- and 28-day curing. At 14- and 28-day curing, the loss in strength decreased significantly. This may be due to the pozzolanic reaction between lime and soil mineral, as reported earlier, which resulted in the formation of a tougher water insoluble gel of calcium silicates with higher strength gain. Consequently, there was limited penetration of the oil which was responsible for loss in strength. It was also observed from the results that reduction in UCS as a result of contamination was less at higher lime content. This is due to the formation of more cementing material at higher lime content because more lime was available for reaction to take place.

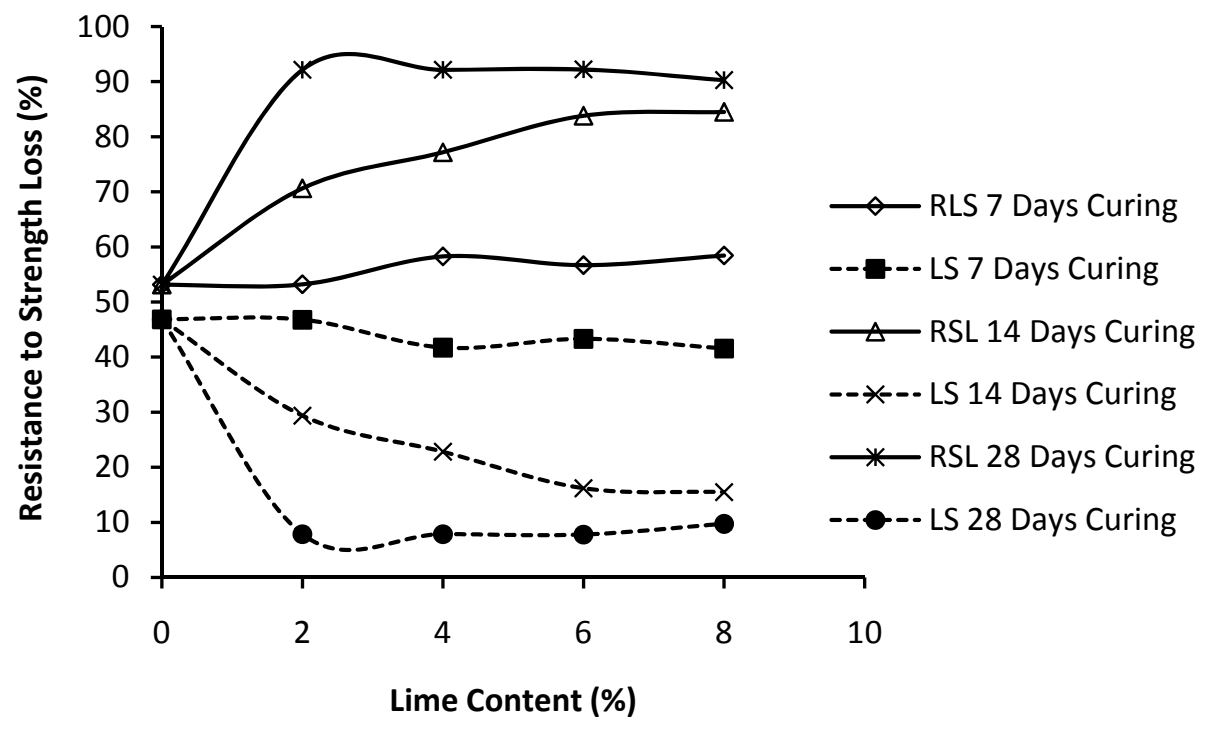

Figure (3): Variation of LS and RSL with lime content for contaminated soil-lime mixture

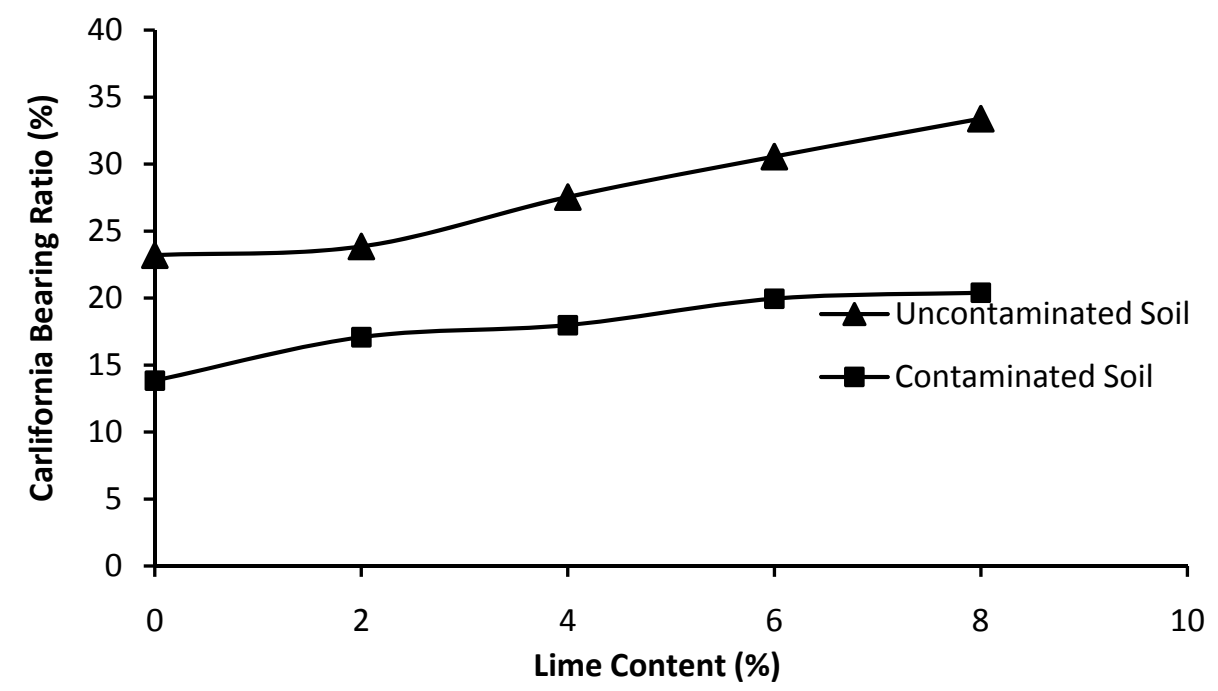

Figure (4): Variation of CBR with lime content for contaminated and uncontaminated soil-lime mixture 


\section{Effect of Spent Oil Contamination on CBR}

The California bearing ratio (CBR) value of a soil is an important parameter used to indicate its strength and bearing capacity. It is widely used in design and to assess the suitability of soil or otherwise for base and sub-base. CBR test is, therefore, a familiar test used to evaluate the strength of soils for these applications.

Fig. 4 shows the plot of CBR values for both contaminated and uncontaminated treated soil. It can be seen from the plot that CBR values increase with lime content but decrease when the soil-lime mixture was contaminated with spent oil at all lime contents. This result shows a reduction of about 35\% in strength of the contaminated soil-lime mixture.

\section{REFERENCES}

Amer, A., Hossam, F. H., Ramzi, T., Abdulwahid, H., Bader, A., and Yahia, A. (2005). "Stabilization of Oilcontaminated Soils Using Cement and Cement By-pass Dust". Management of Environmental Quality: An International Journal, 16 ISS (6), 670-680.

BS1377. (1990). "Methods of Testing Soils for Civil Engineering Purposes". British Standard Institution, London.

BS1924. (1990). "Methods of Test for Stabilized Soils". British Standard Institution, London.

Clare, K. E., and Cruchley, A. E. (1957). "Laboratory Experiments on the Stabilization of Clays with Hydrated Lime”. Geotechnique, 7, 97-100.

Dana, A. A., and Ahmad, A. A. (2011). $2^{\text {nd }}$ International Conference on Environmental Science and Technology IPCBEE, Vol. 6, IACSIT Press, Singapore.

Eades, J. L., and Grim, R. E. (1960). "Reaction of Hydrated Lime with Pure Clay Minerals in Lime Stabilization". Highway Res. Bull., Washington, D. C., 262, 51-63.

\section{CONCLUSIONS}

This study evaluates the effect of spent oil contamination on the strength of lime stabilized soil. The results obtained show that the strength of lime stabilized soil decreased when contaminated with oil. The value of UCS decreased by about 46, 23 and $13 \%$ for soil-lime mixture cured for 7, 14 and 28 days, respectively. Similarly, CBR value of the soil-lime mix reduced by about 35\%. It was also observed that the resistance to loss in strength increased with lime content and curing period. This results show for all practical purposes that a lime stabilized pavement structure exposed to oil contamination is susceptible to failure as a result of reduction in strength and bearing capacity.

Evgin, E., and Das, B. M. (1992). "Mechanical Behaviour of Oil-contamniated Sand". In: Environmental Geotechnology, Usmen, M.A., and Y.B. Acar (Eds.). Balkema Publishers, Rotterdam, Netherlands, 101-108. Ijimdiya, T.S., and Igboro, T. (2012). "Effect of Used Oil on the Strength and Compressibility Behaviour of Lateritic Soil". In: Laryea, S., Agyepong, S.A., Leiringer, R., and Hughes, W. (Eds.) Procs. $4^{\text {th }}$ West Africa Built Environment Research (WABER) Conference, 24-26 July 2012, Abuja, Nigeria, 715-723.

Ingles, O. G., and Metcalf, J. B. (1972). Soil Stabilization. Butterworths, Melbourne, Australia.

ISSMFE Progress Report. (1982/1985). "Peculiarities of Geotechnical Behaviour of Tropical Lateritic and Saprolitic Soils.” Committee on Tropical Soils of the ISSMFE.

Khamehchiyan, M., Charkhabi, A. H., and Tajik, M. (2007). "Effects of Crude Oil Contamination on Geotechnical Properties of Clayey and Sandy Soils". Eng. Geol., 89, 220-229.

Locat, Y., Berube, M. A., and Choquette, M. (1990). "Laboratory Investigation on the Lime Stabilization of Sensitive Clays; Shear Strength Development". Can. Geotechnical Journ., 27, 294-304. 
Narasimha Rao, and Rajesekaran, G. (1996). "Reaction Products Formed in Lime Stabilized Marine Clays". Journ. Geotechnical Engrg. Div., ASCE, 122 (5), 329336.

Ola, S.A. (1975). "Stabilization of Nigerian Laterite Soils with Cement, Bitumen and Lime", Proceedings of the Sixth Regional Conference for Africa on Soil Mechanics and Foundation Engineering, Durban, 1, 145-152.

Ormsby, W.C., and Kinter, E.B. (1973). "Strength Development and Reaction Products in LimeMontmorillonite-Water Systems". Public Roads, 37 (4), $136-148$

Osinubi, K. J. (1999). "Influence of Compaction Delay on the Properties of Lime- stabilised Lateritic Soil." Journal of Engineering Research, JER-7, (1 \& 2), 129142.
Osinubi, K. J., and Nwaiwu, M. O. C. (2006). "Compaction Delay Effects on the Properties of Lime-treated Soil". Jour. of Material in Civil Engineering, ASCE, 18 (2), 250-258.

Shah, S. J., Shroff, A. V., Jingnesh, V. P., Tiwari, K. C., and Ramakrishnan, D. (2003). "Stabilizaton of Fuel Conatimated Soil- A Case Study". Geotechnical and Geological Engineering, 21-PP415-427, Kluwer Academic Publishers, Netherlands.

Shin, E.C., and Das, B. M. (2001). "Bearing Capacity of Unsaturated Oil-contaminated Sand". Int. Jour. Offshore Polar Eng., 11, 220-227.

Thompson, M. R. (1966). "Lime Reactivity of Illinois Soils". Journal of Soil Mechanics and Foundation Engineering Div., ASCE, 96, 120-123. 